\title{
BMJ Open Non-interventional study evaluating exposure to inhaled, low-dose methoxyflurane experienced by hospital emergency department personnel in France
}

\author{
John Frangos, ${ }^{1}$ Anissa Belbachir, ${ }^{2}$ Sandrine Dautheville, ${ }^{3}$ Christiane Jung, ${ }^{4}$ \\ Key Herklotz, ${ }^{4}$ Freya Amon, ${ }^{1}$ Sara Dickerson (iD , ${ }^{5}$ Berangere Chomier ${ }^{6}$
}

To cite: Frangos J, Belbachir A, Dautheville S, et al. Noninterventional study evaluating exposure to inhaled, low-dose methoxyflurane experienced by hospital emergency department personnel in France. BMJ Open 2020;10:e034647. doi:10.1136/ bmjopen-2019-034647

- Prepublication history for this paper is available online. To view these files, please visit the journal online (http://dx.doi. org/10.1136/bmjopen-2019034647).

Received 29 September 2019 Revised 21 January 2020 Accepted 23 January 2020
D) Check for updates

(c) Author(s) (or their employer(s)) 2020. Re-use permitted under CC BY-NC. No commercial re-use. See rights and permissions. Published by BMJ.

For numbered affiliations see end of article.

\section{Correspondence to}

Dr Sara Dickerson;

sara.dickerson@mundipharma. com

\section{ABSTRACT}

Objectives Low-dose methoxyflurane is a non-opioid, inhaled analgesic administered via the Penthrox inhaler and was recently licensed in Europe for emergency relief of moderate-to-severe trauma-associated pain in conscious adults. This non-interventional study investigated occupational exposure to methoxyflurane in the hospital emergency department (ED) personnel during routine clinical practice.

Setting and participants The study was conducted in two hospital ED triage rooms in France over a 2-week and 3-week period, respectively. Low-dose methoxyflurane analgesia was self-administered by patients via the inhaler under the supervision of nursing staff, per routine clinical practice. An organic vapour personal badge sampler was attached to the uniform of the nurses working in the treatment rooms throughout an 8-hour shift (total of 140 shifts during the study period). Seven-day ambient air monitoring of each treatment room was also performed. Methoxyflurane levels adsorbed in each badge sampler were measured by a central laboratory. The primary objective was to evaluate methoxyflurane exposure experience by the hospital ED nurses during an 8-hour shift.

Results In 138 badge samplers, the median (range) concentration of methoxyflurane present following 8-hour nursing shifts was $0.017(0.008,0.736) \mathrm{ppm}$. This level was almost 900 -fold lower than the previously reported 8-hour-derived maximal exposure level of $15 \mathrm{ppm}$; methoxyflurane exposure approaching this threshold was not documented in any badges. There was no correlation between the number of applications of low-dose methoxyflurane administered during a shift (range 0-5) and the vapour exposure measured on the personal badge samplers.

Conclusions This study indicates that nurses working in hospital EDs experience very low levels of occupational exposure to methoxyflurane vapour during routine clinical practice. These real-world data can provide reassurance to healthcare providers supervising patients receiving low-dose methoxyflurane analgesia via a Penthrox inhaler; further studies may inform exposure in other hospital ED settings.
Strengths and limitations of this study

- This is the first real-world study to inform exposure of hospital emergency department staff to methoxyflurane vapour when supervising patients selfadministering analgesia via the hand-held Penthrox inhaler.

- The low levels of methoxyflurane vapour detected on organic vapour personal badge monitors worn by hospital emergency department nurses during routine clinical practice may provide reassurance to healthcare professionals.

- A key limitation is that this study included nurses working in just two emergency treatment rooms in France, supervising the use of $\leq 5$ applications of Penthrox inhalers per 8-hour shift.

- It is feasible that healthcare professionals supervising the use of Penthrox inhalers more frequently and/or in smaller rooms without ventilation systems may experience higher exposure to methoxyflurane than reported in the present study.

\section{INTRODUCTION}

Effective management of moderate-tosevere pain in emergency medicine is a crucial element of patient care. In Europe, approximately 38 million injured patients are treated each year in hospital emergency departments, and pain is the primary reason for most patients visiting the emergency department. ${ }^{1-3}$ Unfortunately, undertreatment of pain in emergency settings is common. Indeed, large-scale studies of European hospital emergency departments indicate fewer than one third of patients with moderate-to-severe pain receive analgesia. ${ }^{34}$

Numerous barriers to the effective treatment of pain in emergency settings have been identified including lack of pain management guidelines and inadequate assessment of pain. ${ }^{5}$ Limitations associated with commonly 
used analgesics can also contribute to oligoanalgesia. For example, although morphine, fentanyl and oxycodone can provide effective pain relief when used appropriately, some healthcare providers (HCPs) are reluctant to administer opioids, due in part to concerns regarding dependency, respiratory depression and other challenging side effects. ${ }^{56}$ Inhaled $\mathrm{N}_{2} \mathrm{O}$ and intravenous or intramuscular ketamine can also provide effective relief for moderateto-severe pain in emergency settings. ${ }^{7}$ However, the use of $\mathrm{N}_{2} \mathrm{O}$ and ketamine may be limited by bulky equipment with limited portability and concerns regarding psychological manifestations and long-term psychotomimetic effects, respectively. ${ }^{5} 99$ Furthermore, safety concerns regarding exposure of HCPs to $\mathrm{N}_{2} \mathrm{O}$ prior to the routine use of waste gas scavenging systems resulted in occupational exposure limits (eg, UK has a 100 ppm 8-hour timeweighted average (TWA) exposure limit for $\mathrm{N}_{2} \mathrm{O}$ ) ${ }^{1011}$ and guidance to minimise potential risks to HCPs have been issued. $^{12} 13$

Low-dose methoxyflurane is an inhaled, non-opioid analgesic which has been used for over 40 years in Australia to provide short-term relief of acute pain in adults and children. ${ }^{14-16}$ In 2015, low-dose methoxyflurane was approved in some European countries for emergency relief of moderate-to-severe trauma-associated pain in conscious adults, and is now approved more widely in Europe, including Spain, Italy, France and UK, as well as in countries in Asia, Latin America, Gulf Area and South Africa. ${ }^{17} 18$ Methoxyflurane was first used at higher doses in the 1960s for general anaesthesia. However, reports of renal tubule damage emerged in some patients following prolonged exposure to this fluorinated hydrocarbon, thought to be caused by elevated levels of inorganic fluoride. ${ }^{19} 20$ Use of methoxyflurane anaesthesia subsequently declined before being voluntarily withdrawn from the market. ${ }^{16}{ }^{1920}$ In contrast to high anaesthetic doses of methoxyflurane, laboratory and clinical data indicate no increased risk of renal toxicity associated with low, analgesic doses. ${ }^{20}$ Exposure to inhaled anaesthetics is commonly assessed using the minimum alveolar concentration (MAC) required for surgical anaesthesia in $50 \%$ of patients. At $\leq 2$ MAC-hours, methoxyflurane results in serum fluoride concentration $\leq 40 \mu \mathrm{mol} / \mathrm{L}$, which is not associated with renal toxicity. ${ }^{20}$ Analgesic use of low-dose methoxyflurane up to $6 \mathrm{~mL}$ in accordance with current treatment recommendations results in methoxyflurane exposure of 0.6 MAC-hours, providing a 2.7-fold to 8-fold renal safety margin. ${ }^{20}$

Low-dose methoxyflurane is self-administered via the hand-held Penthrox 'green whistle' inhaler. Each inhaler provides a $3 \mathrm{~mL}$ dose of methoxyflurane $99.9 \%$, which provides analgesia for 25-30 min with continuous inhalation or longer analgesic relief if used intermittently, as is recommended. ${ }^{17}$ Patients may receive a maximum of two $3 \mathrm{~mL}$ vials of methoxyflurane in a single administration and $\leq 15 \mathrm{~mL} /$ week on non-consecutive days. ${ }^{17}$ Methoxyflurane is added to the inhaler via a one-way valve and is absorbed by a polypropylene wick. Following instruction from an HCP trained in the use of the inhaler, the patient inhales the vaporised liquid through the mouthpiece and exhales back into the mouthpiece. Exhaled methoxyflurane is captured by an activated carbon (AC) chamber fitted to the inhaler in order to minimise environmental exposure. If stronger analgesia is required, then the patient can cover the dilutor hole on the AC chamber (figure 1). ${ }^{16}$ In vitro testing indicates that methoxyflurane concentrations delivered by the Penthrox inhaler can reach a peak of $0.7 \%$ when the dilutor hole in the AC chamber is closed, and methoxyflurane concentrations are reduced by approximately $20 \%$ when the dilutor hole is open.

Despite the AC chamber to capture the exhaled methoxyflurane, when supervising patients receiving inhaled analgesia within a confined area, it is possible that HCPs may experience intermittent exposure to methoxyflurane vapour. A formal limit regarding levels of occupational exposure to methoxyflurane has not been established. However, a maximum of 8-hour TWA exposure limit of $15 \mathrm{ppm}$ was derived based on the extrapolation of nephrotoxicity data from anaesthetized patients receiving high-dose methoxyflurane. ${ }^{21}$ This benchmark is well above the methoxyflurane odour threshold of

1. Penthrox inhaler is tilted to a $45^{\circ}$ angle and the contents of one bottle poured into the base while rotating

2. Patient inhales intermittently through the mouthpiece to obtain analgesia (continuous inhalation reduces the duration of use)

3. Patient exhales into the inhaler. The exhaled vapour passes through the activated carbon chamber to adsorb exhaled methoxyflurane

4. If stronger analgesia is required, the patient can cover the diluter hole with their finger

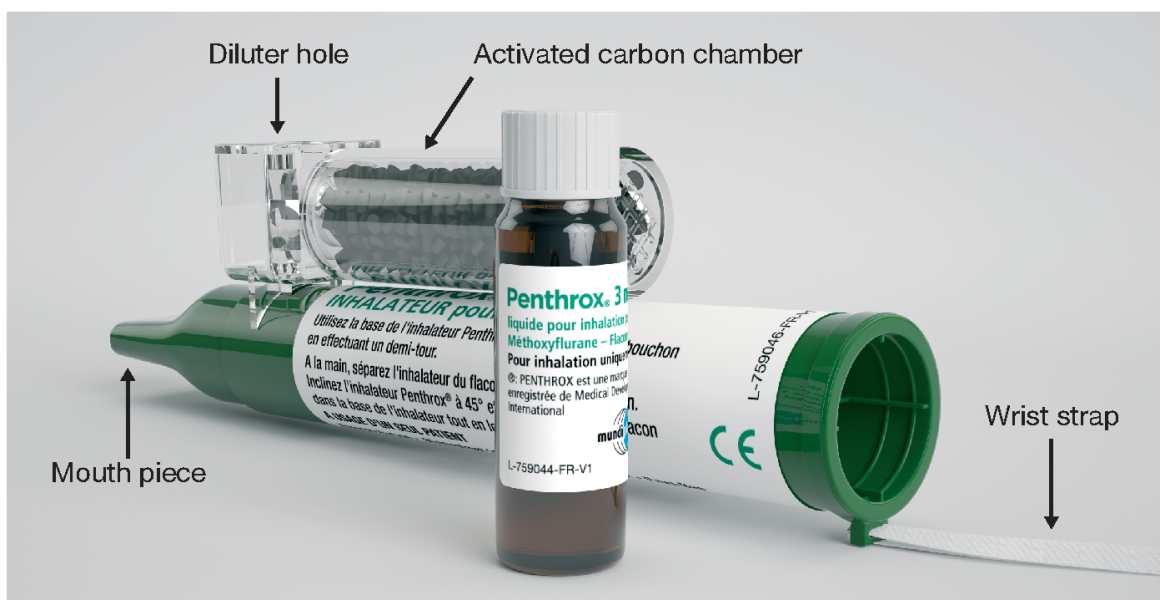

Figure 1 Use of the Penthrox inhaler (permission to reproduce the image was provided by Mundibiopharma limited). ${ }^{17}$ 
0.13-0.19 ppm. ${ }^{21}$ Although low levels of methoxyflurane exposure have been documented in ambulance personnel and hospital staff supervising patients using Penthrox inhalers during painful procedures, studies are lacking to inform occupational exposure of hospital emergency department staff to methoxyflurane vapour. ${ }^{21-23}$

The aim of this real-world study was to investigate occupational exposure to methoxyflurane experienced by hospital emergency room nurses when overseeing patients using low-dose, inhaled methoxyflurane analgesia during routine clinical practice.

\section{METHODS}

This non-interventional study was conducted in two medium-sized public assistance hospitals in Paris, France: Cochin Hospital and Tenon Hospital (51080 and 43953 patients were admitted to each hospital emergency department in 2015, respectively). The study was conducted over a 3-week and 2-week period at Cochin Hospital and Tenon Hospital, respectively. The shorter study duration at Tenon Hospital reflects a 1-week feasibility study performed at this site prior to initiating the main study. This was conducted at the request of Agence Générale des Equipements et Produits de Santé (AGEPS), a group representing hospitals in Paris, in order to assess the feasibility of the proposed use, storage and analysis of the badge samplers described below. The study was conducted in one emergency department triage room at each site (Cochin Hospital room volume $\sim 43 \mathrm{~m}^{3}$ and Tenon Hospital room volume $\sim 102 \mathrm{~m}^{3}$ ); both rooms were windowless and had air ventilation systems.

Low-dose methoxyflurane analgesia was administered by patients via the Penthrox inhaler under the supervision of trained triage nursing staff and per routine clinical practice. Exposure of the triage nurse to methoxyflurane was assessed using 3M Organic Vapor Monitor 3500 personal badge samplers, which contain a charcoal adsorbent pad (figure 2). ${ }^{24} 3 \mathrm{M}$ Organic Vapor Monitor 3500 badge samplers are specifically designed
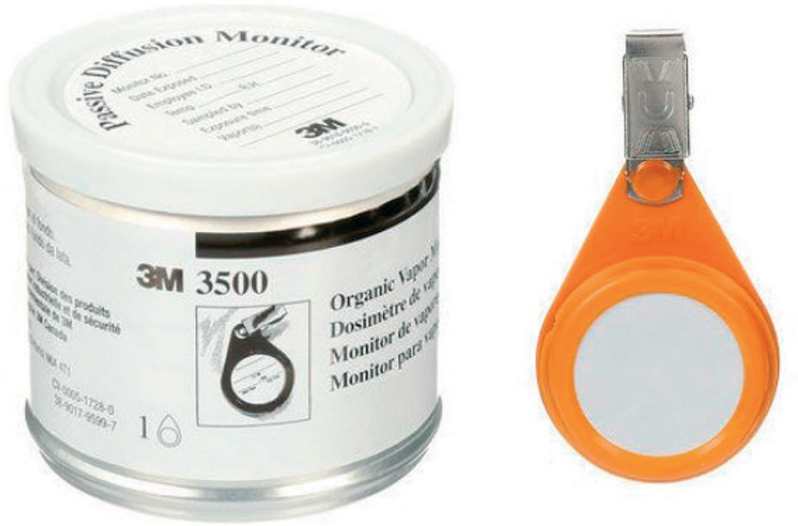

Figure 2 3M Organic Vapour Monitor 3500 packaging box and badge sampler (permission to reproduce the image was provided by $3 \mathrm{M}){ }^{30}$ to monitor personal and area exposure to a wide range of organic vapours. They were selected for this study based on the ease of use, as well as being small and lightweight, thereby minimising interference with nursing activities. These badge samplers have been validated across a range of settings and the following use can be stored at room temperature or refrigerated for $\leq 21$ days prior to analysis. ${ }^{25}$ The monitoring of methoxyflurane by the personal badge samplers required a sampling rate of $27.8 \mathrm{~mL} / \mathrm{min}$ and a minimum air velocity of $13 \mathrm{~cm} / \mathrm{s}$.

In accordance with the manufacturer's instructions, each triage nurse attached a badge sampler to the chest region on their uniform which was worn throughout their 8-hour shift. The selection of the nurses who wore the badges was based on hospital rotas; no other selection criteria were applied. Prior to use, the badge samplers were stored in a locked cupboard. At the end of the shift the nurse packaged their badge sampler in aluminium foil and placed it in a designated sealed container where it was stored in a refrigerator for up to 1 week prior to delivery to the laboratory for analysis. Continuous, 7-day ambient air monitoring of both emergency department triage rooms was also conducted. A personal badge sampler was suspended from the ceiling of each room in the vicinity of the patient treatment area while not impeding clinical procedures or being easily reached by hand. Prior to the study start, the nurses underwent training on the use, package and storage of the badge samplers and were provided with a protocol. Nurse coordinators also oversaw the correct use and storage of the badges.

Four badge samplers were worn daily at each hospital: two by nurses during the morning/afternoon shift and two by nurses during the afternoon/evening shift (badges worn during a total of 140 8-hour shifts were planned). At the end of each week, the 28 badge samplers were collected from each hospital along with the 7-day ambient air monitor. A 'trip blank' sampler (unopened and unworn badge sampler, repackaged for transportation to the laboratory) was also included to assess potential cross contamination during storage/transport.

Analysis of the badge samplers and ambient air monitors was performed by a central laboratory accredited for the analysis of organic compounds in ambient and workplace air (öko-control GmbH laboratory, Germany). The badge samplers underwent ultrasound extraction for 10 min with carbon disulfide. Quantification of methoxyflurane was performed using a validated gas chromatography-mass spectrometry platform and included a toluene internal standard. Methoxyflurane samples for assay calibration were provided by Mundipharma.

TWA concentration of methoxyflurane present in every badge sampler was calculated using the following equation which assumed a sampling rate of $27.8 \mathrm{~mL} / \mathrm{min}$ :

$$
\begin{aligned}
& \mathrm{A}=1000 / \mathrm{SR} \\
& C\left(\mathrm{mg} / \mathrm{m}^{3}\right)=W \cdot A / r \cdot t \\
& C(\mathrm{ppm})=C\left(\mathrm{mg} / \mathrm{m}^{3}\right) \cdot M_{v} / M_{W}
\end{aligned}
$$


(A=calculation constant; $C$, concentration; $\mathrm{SR}=\mathrm{sam}-$ pling rate $(\mathrm{mL} / \mathrm{min}) ; W=$ mass $(\mu \mathrm{g} / \mathrm{sample}) ; M_{V}=$ molar vol $(\mathrm{L} / \mathrm{mol}) ; M_{W}=$ molecularwt $(\mathrm{g} / \mathrm{mol}) ; r=$ recovery coefficient; $t=$ sampling time ( $\mathrm{min})$

Samples with methoxyflurane concentrations below the lower limit of quantification $(1 \mu \mathrm{g} / \mathrm{sample})$ were assigned a value of $0.7 \mu \mathrm{g} / \mathrm{sample}$ for calculation purposes, as a conservative approach. Methoxyflurane concentrations are described using summary statistics for each study site and across the entire study (statistical testing was not performed).

Institutional Review Board (IRB) approval for this study was not sought as this was not a clinical trial, measurement of methoxyflurane levels did not require an invasive procedure and no patient data were collected. Furthermore, occupational exposure risk in France is managed by the ministry of work Institut National de Recherche et de Sécurité (INRS).

\section{Patient and public involvement}

This study was undertaken without patient or public involvement.

\section{RESULTS}

Passive air sampling was conducted at Cochin Hospital between 25 April 2018 and 16 May 2018, and at Tenon Hospital between 02 May 2018 and 15 May 2018. In total, 138 staff badges were analysed: 83 from Cochin Hospital and 55 from Tenon Hospital (one planned badge was not obtained from each study site). Methoxyflurane concentrations were below the assay quantification limit $(1 \mu \mathrm{g} / \mathrm{sample})$ in 30 and 31 badge samplers from Cochin and Tenon Hospitals, respectively, and were assigned a methoxyflurane concentration of $0.7 \mu \mathrm{g}$. Concentrations of methoxyflurane assessed in the 'trip blank' control samples were at or below the assay quantification limit.

As shown in figure 3, methoxyflurane concentrations recorded in all the personal badge samplers were substantially lower than the previously reported maximum 8-hour exposure limit of $15 \mathrm{ppm} .{ }^{21}$ Across both hospital emergency rooms, the median (range) concentration of methoxyflurane assayed in the badge samplers following 8-hour nursing shifts was 0.017 $(0.008,0.736) \mathrm{ppm}$. Median (range) methoxyflurane concentrations in the badge samplers obtained from Cochin Hospital $(0.020 \quad(0.009,0.736)$ ppm $)$ were approximately twofold greater than those from Tenon Hospital (0.011 (0.008, 0.079); figure 4). This finding may reflect higher 'outlier' concentrations of methoxyflurane detected in two badge samplers from Cochin Hospital (0.736 and $0.319 \mathrm{ppm}$ ).

The number of low-dose methoxyflurane applications administered in the two treatment rooms during each nursing shift ranged from 0 to 5 . There was no apparent correlation between the number of applications of lowdose methoxyflurane administered during a shift and the vapour exposure measured on the personal badge samplers worn during that period (figure 5).

Very low concentrations of methoxyflurane were also detected during 7-day continuous monitoring of ambient air in the two emergency triage rooms: Cochin Hospital $0.01,0.02$ and $0.024 \mathrm{ppm}$ (study weeks 1,2 and 3, respectively); Tenon Hospital: 0.011 and 0.002 ppm (study weeks 1 and 2, respectively).

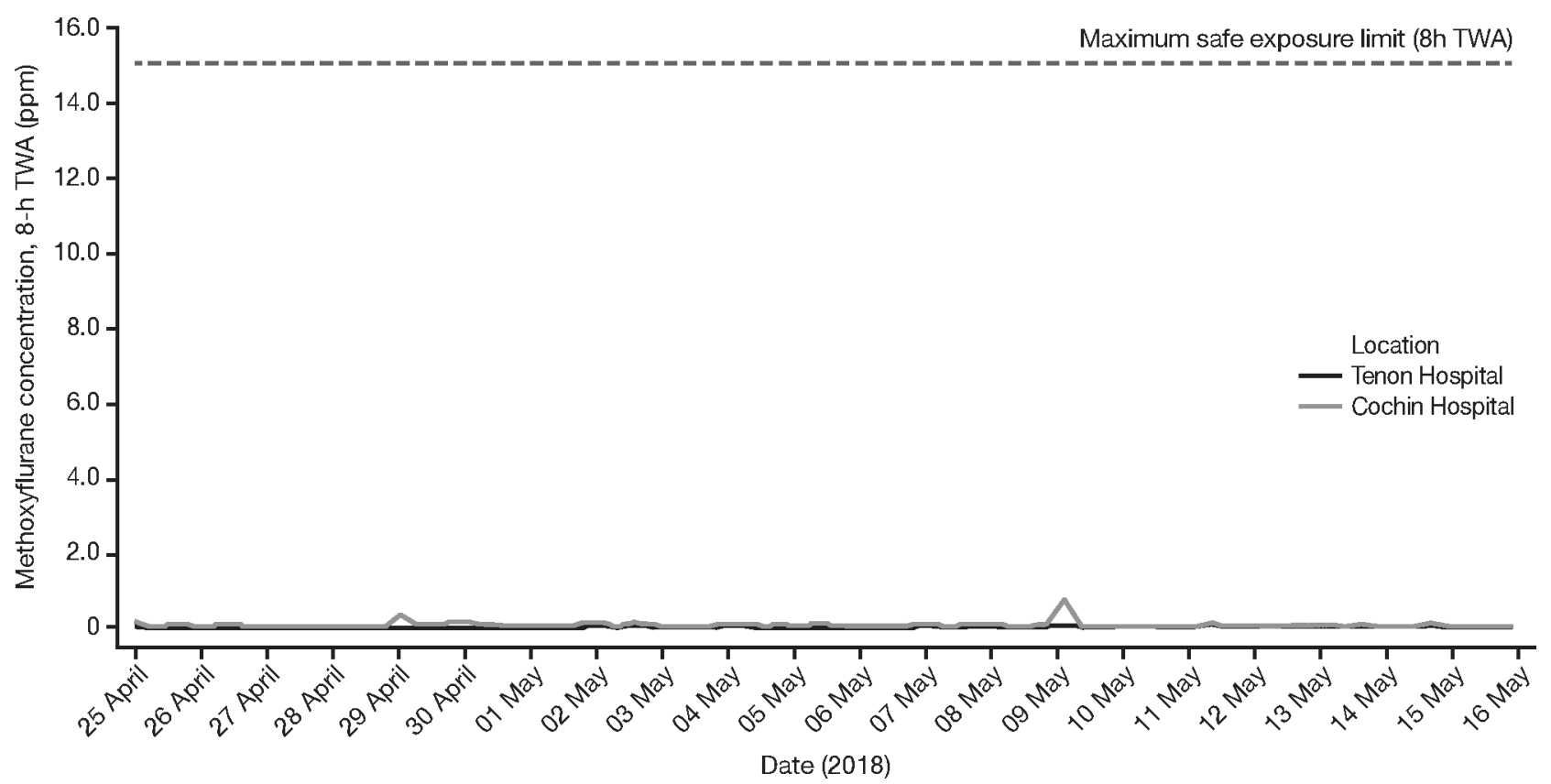

Figure 3 Methoxyflurane concentrations over time, as detected in personal badge samplers worn by emergency room nurses during 8-hour shifts. Maximum TWA exposure level of $15 \mathrm{ppm}$ during an 8-hour period (hashed line) was based on a previously reported extrapolation of nephrotoxicity data obtained from anaesthetised patients receiving high-dose methoxyflurane. ${ }^{21}$ TWA, time-weighted average. 


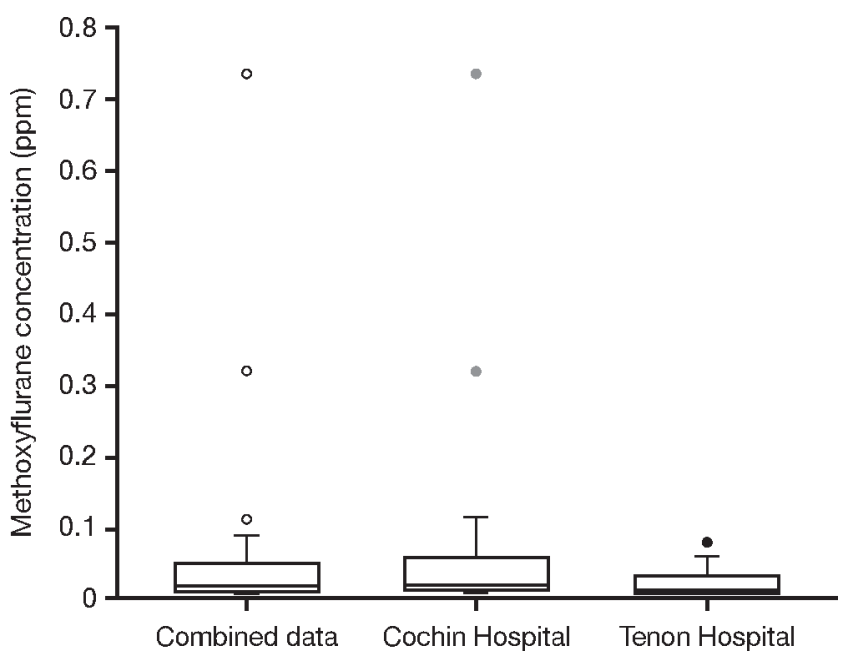

Figure 4 Box plots capturing methoxyflurane concentrations measured in personal badge samplers worn by emergency room triage nurses during 8-hour shifts. Box represents IQR and median values. Whiskers represent the minimum (first quartile $-1.5 \times \mid \mathrm{QR}$ ) and maximum (third quartile $+1.5 \times$ IQR). Outliers are shown in circles. Methoxyflurane concentrations were below the quantification limit $(1 \mu \mathrm{g} /$ sample) in 30 and 31 badge samplers from Cochin Hospital and Tenon Hospital, respectively. For calculation purposes, these samples were assigned a concentration of $0.7 \mu \mathrm{g}$.

\section{DISCUSSION}

Low-dose methoxyflurane, administered via the Penthrox inhaler, can provide effective non-opioid analgesia. ${ }^{16}$ It is licensed in Europe for emergency relief of moderate-tosevere trauma-associated pain in conscious adults. ${ }^{17}$ This approval was based on the double-blind, randomised, placebo-controlled STOP! trial, in which effective pain control with a rapid onset of action (median onset of pain relief was $4 \mathrm{~min}$ ) was reported in adults and adolescents presenting at hospital emergency departments with trauma-related pain. ${ }^{26}$ Low-dose methoxyflurane has also been shown to provide effective analgesia during painful medical procedures including burn dressing changes, abscess drainage, colonoscopy and removal of brachytherapy rods. ${ }^{27} 28$ Although the Penthrox inhaler is fitted with an AC chamber to minimise environmental exposure to methoxyflurane, HCPs may inadvertently inhale low quantities of the vapour. For example, this may occur if a patient fails to exhale directly into the inhaler, despite receiving instruction on correct usage. To our knowledge, this is the first study to examine occupational exposure of HCPs to methoxyflurane when supervising patients administering this analgesic in hospital emergency departments during routine clinical practice.

This real-world study, conducted in two treatment rooms at hospitals in Paris, examined methoxyflurane vapour exposure experienced by emergency department triage nurses. In total, 138 passive diffusion badge samplers were worn by nurses throughout their 8-hour work shifts. Assessments revealed that during the usual use of the Penthrox inhaler, the triage nurses were exposed to extremely low concentrations of methoxyflurane vapour. No individuals

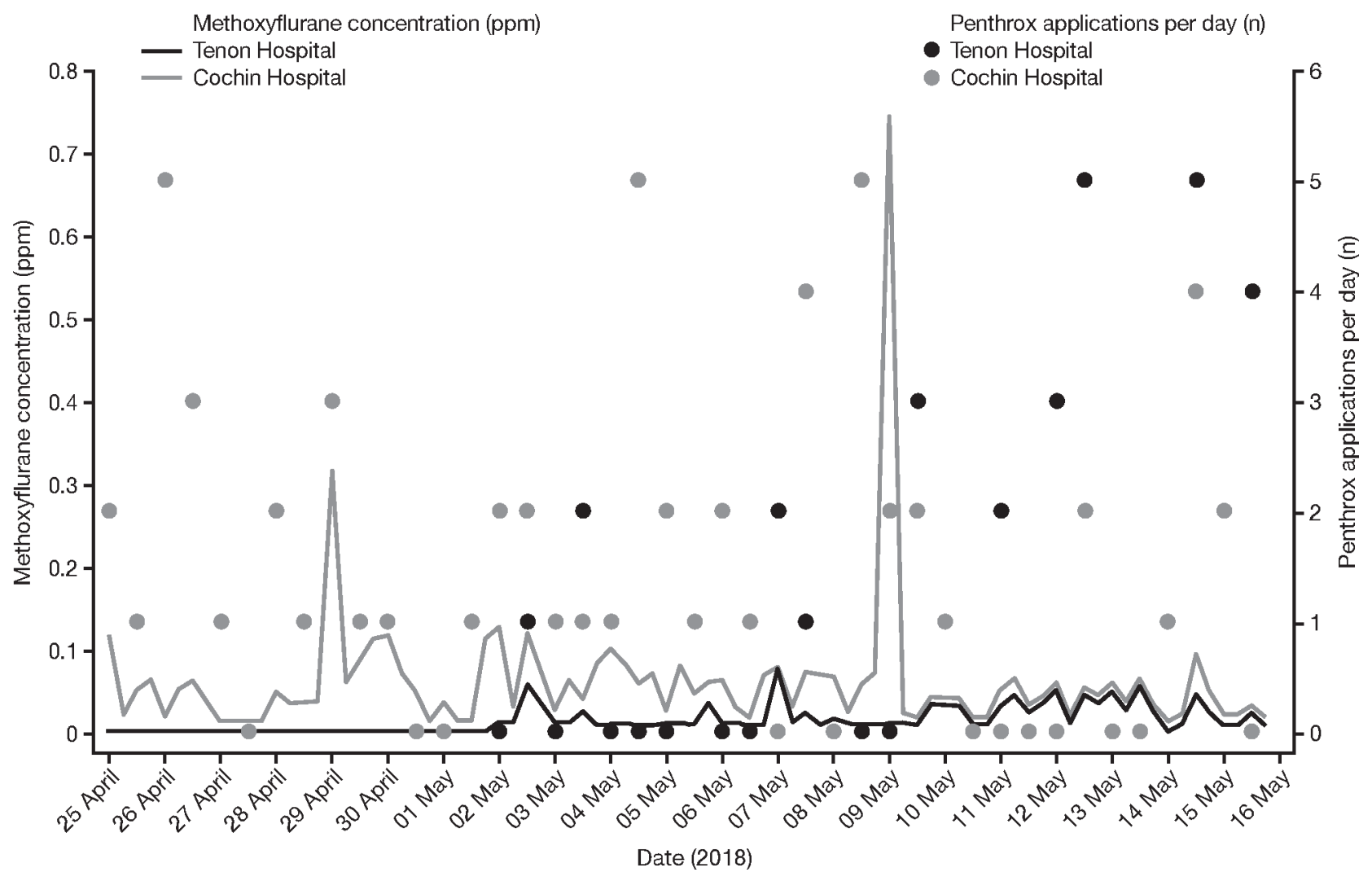

Figure 5 Methoxyflurane vapour concentrations measured in personal badge samplers ${ }^{\star}$ and number of Penthrox applications per day. *Worn by emergency room triage nurses throughout an 8-hour shift. 
experienced methoxyflurane exposure approaching the previously reported maximum 8-hour exposure limit of 15 ppm. ${ }^{21}$ The median (range) exposure to methoxyflurane measured on the badge samplers at both sites during an 8-hour shift was $0.017(0.008,0.736) \mathrm{ppm}$, almost 900fold lower than the $15 \mathrm{ppm}$ exposure limit. Similarly, very low concentrations of methoxyflurane were also detected during 7-day continuous monitoring of ambient air in the two emergency rooms $(\leq 0.024 \mathrm{ppm})$, supporting these findings. The reason for lower median (range) methoxyflurane concentrations detected in the badge samplers from Tenon Hospital (0.011 (0.008, 0.079) ppm) compared with Cochin Hospital (0.020 (0.009, 0.736) $\mathrm{ppm}$ ) is unclear, and may in part reflect the smaller treatment room dimensions of the latter (102 vs $\left.43 \mathrm{~m}^{3}\right)$.

Compared with other badge samplers, higher concentrations of methoxyflurane were recorded in two personal badges, although at concentrations substantially lower than the $15 \mathrm{ppm}$ exposure limit: 0.736 and $0.319 \mathrm{ppm}^{21}$ These higher concentrations cannot be explained by greater use of Penthrox inhalers on these occasions as they were detected following nursing shifts supervising 2 and 3 methoxyflurane applications (range across the study was $0-5$ applications) and no correlation was found between the number of methoxyflurane applications and exposure levels. Although this study was not designed to elucidate reasons for exposure variation, potential sources may include patients not exhaling into the AC chamber of the Penthrox inhaler, spillage of methoxyflurane while filling the inhaler and failure to place used inhalers in sealed plastic bags.

Findings from this real-world study are supported by investigations in other settings that also indicate that HCPs experience very low occupational exposure to methoxyflurane vapour when supervising patients using the Penthrox inhaler. For example, median (range) 8-hour TWA exposure to methoxyflurane was 0.38 (0.18-2.88) ppm in nurses and haematologists attending patients using the inhalers during procedural sedation for bone marrow biopsies. ${ }^{22}$ Frangos et al reported mean 8-hour TWA methoxyflurane exposure experienced by paramedics to be $0.23 \mathrm{ppm}$ when the inhalers were used without the activated charcoal chamber in the confines of an ambulance. ${ }^{21}$ Re-analysis of these data using a bootstrap approach also indicated that ambulance crews are exposed to low levels of methoxyflurane vapour. ${ }^{23}$

To date, only limited reports of mild, non-serious adverse events have been reported by paramedical and medical staff following occupational exposure to methoxyflurane vapour. Although it cannot be determined whether these events were associated with the use of the Penthrox inhaler by appropriately trained patients, the scarcity of safety reports from HCPs worldwide supports the findings of extremely low levels of methoxyflurane detected in badge samplers of nurses supervising its analgesic use in the present study. However, it is recommended that HCPs who are regularly exposed to patients using the inhalers should be aware of any relevant occupational health and safety guidelines for the use of inhalational agents. ${ }^{17}$ Furthermore, to reduce occupational exposure to methoxyflurane, the Penthrox inhaler should always be used with the AC chamber which adsorbs exhaled methoxyflurane (figure 1). ${ }^{17}$

Low-dose methoxyflurane analgesia was well tolerated by adults and adolescents with trauma-related pain in the pivotal STOP! trial (the most frequent adverse events were headache and dizziness) and analysis of 135770 patients receiving methoxyflurane analgesia in the prehospital setting in Australia indicated no increased risk for heart disease, hepatic disease, diabetes, cancer or renal disease associated with this treatment. ${ }^{29}$ Nevertheless, and despite low-dose methoxyflurane use being associated with low serum fluoride levels which do not impact renal safety, methoxyflurane analgesia is contraindicated in patients with clinically significant renal impairment and should not be used in conjunction with medicines known to have a nephrotoxic effect. ${ }^{170}$ Caution should also be exercised in patients with risk factors for renal disease or hepatic dysfunction. ${ }^{17}$

Although this study aimed to reflect real-world exposure to low-dose methoxyflurane experienced by nurses in hospital emergency departments, as with all observational studies it was associated with structural limitations and potential biases. For example, assessment of methoxyflurane vapour exposure for hospital emergency department nurses was limited to individuals working in just two emergency treatment rooms with $\leq 5$ applications of Penthrox inhalers used per shift. Consequently, these data may not reflect methoxyflurane exposure for emergency care staff elsewhere. Although based on the authors' experience, the size of the ED triage rooms included in this study (43 and $102 \mathrm{~m}^{3}$ ) and the frequency of Penthrox inhaler administrations supervised by the triage nurses (0-5 applications per shift) are representative of hospital EDs in France, it is conceivable that methoxyflurane exposure levels may be greater for individuals working in smaller emergency rooms, enclosed rooms without ventilation systems and when overseeing greater utilisation of Penthrox inhalers. Of note, exposure modelling based on a treatment room smaller than included in the present study $\left(32.4 \mathrm{~m}^{3}\right.$ ) with six air changes per hour (in line with Australian guidelines) alongside a substantially higher usage rate of Penthrox inhalers (two applications every hour) indicated an 8-hour TWA exposure of $1.48 \mathrm{ppm}$, which is substantially lower than the previously calculated safety threshold of 15 ppm. ${ }^{21}$

\section{CONCLUSIONS}

In summary, results from this study indicate that triage nurses working in hospital emergency departments experience very low levels of occupational exposure to methoxyflurane vapour during routine clinical practice. During an 8-hour work shift exposure to methoxyflurane was substantially lower than the previously calculated maximum threshold of $15 \mathrm{ppm}$ in all individuals (median (range) 
$0.017(0.008-0.736) \mathrm{ppm})$ and was below the minimum level of detection in almost half badge samples analysed. These data can provide reassurance to HCPs supervising patients receiving low-dose methoxyflurane analgesia via a Penthrox inhaler fitted with an activated AC.

\section{Author affiliations}

${ }^{1}$ CDM Smith Inc, Melbourne, Victoria, Australia

${ }^{2}$ Emergency Department, Hospital Cochin, Paris, Île-de-France, France

${ }^{3}$ Emergency Department, Hospital Tenon, Paris, Île-de-France, France

${ }^{4} \mathrm{CDM}$ Smith Consult GmbH, Frankfurt, Germany

${ }^{5}$ Medical Affairs, Mundibiopharma Limited, Cambridge, UK

${ }^{6}$ Mundipharma France, Paris, Île-de-France, France

Acknowledgements Medical writing support was provided by Siân Marshall Ph.D. of SIANTIFIX Ltd, Cambridgeshire, UK, and was funded by Mundipharma Research Ltd.Penthrox is a registered trademark of Medical Development International Limited and used under license.

Contributors JF, CJ, KH, FA, SLD and BC: were responsible for protocol design. $A B, S D$ and $C J$ : conducted the study. JF, CJ, KH and FA: analysed the data. JF, $A B$, $\mathrm{SD}, \mathrm{FA}, \mathrm{SLD}$ and BC: interpreted the data. All authors read and approved the final manuscript.

Funding This study was funded by Mundipharma International Ltd. The study sponsor, Mundipharma France, was involved in the study design and had no role in data acquisition, data analysis or data interpretation. CDM Smith were responsible for data acquisition and data analysis. All authors had full access to the study data and participated in writing the report and/or critically reviewing drafts of the manuscript, including those working for the study sponsor, and were involved in the decision to submit the paper for publication.

Competing interests JF, CJ, KH and FA report contract fee to conduct sampling program. $A B$ has nothing to declare. SG was paid travel expenses by Mundipharma France to attend a Congress in 2017. SD is an employee of an affiliation with Mundipharma. BC is an employee of Mundipharma.

Patient consent for publication Not required.

Provenance and peer review Not commissioned; externally peer reviewed.

Data availability statement Data are available upon reasonable request. The datasets generated, analysed and reported within this manuscript may be requested in accordance with the Data Sharing Policy of Mundipharma Research Limited available from https://www.mundipharmaresearch.com/responsibility/ clinical-trials/data-sharing-policy/.

Open access This is an open access article distributed in accordance with the Creative Commons Attribution Non Commercial (CC BY-NC 4.0) license, which permits others to distribute, remix, adapt, build upon this work non-commercially, and license their derivative works on different terms, provided the original work is properly cited, appropriate credit is given, any changes made indicated, and the use is non-commercial. See: http://creativecommons.org/licenses/by-nc/4.0/.

\section{ORCID iD}

Sara Dickerson http://orcid.org/0000-0002-9321-1602

\section{REFERENCES}

1 Kisser R, Walters A, Rogmans W, et al. Injuries in the European Union 2013-2015 (supplementary report). Available: http://www.eurosafe. eu.com/uploads/inline-files/IDB\%202013-2015_suppl\%20to\% 206th\%20edition\%20Injuries\%20in\%20the\%20EU.pdf [Accessed Nov 2019].

2 Karwowski-Soulie F, Lessenot-Tcherny S, Lamarche-Vadel A, et al. Pain in an emergency department: an audit. Eur J Emerg Med 2006;13:218-24.

3 Mura P, Serra E, Marinangeli F, et al. Prospective study on prevalence, intensity, type, and therapy of acute pain in a secondlevel urban emergency department. J Pain Res 2017;10:2781-8.

4 Dale J, Bjørnsen LP. Assessment of pain in a Norwegian emergency department. Scand J Trauma Resusc Emerg Med 2015;23:86.

5 Dißmann PD, Maignan M, Cloves PD, et al. A review of the burden of trauma pain in emergency settings in Europe. Pain Ther 2018;7:179-92.
6 Sinatra R. Causes and consequences of inadequate management of acute pain. Pain Med 2010;11:1859-71.

7 Todd $\mathrm{KH}$. A review of current and emerging approaches to pain management in the emergency department. Pain Ther 2017:6:193-202.

8 Porter KM, Siddiqui MK, Sharma I, et al. Management of trauma pain in the emergency setting: low-dose methoxyflurane or nitrous oxide? A systematic review and indirect treatment comparison. $J$ Pain Res 2018;11:11-21.

9 Jonkman K, Dahan A, van de Donk T, et al. Ketamine for pain. F1000Res 1711;2017:6.

10 Health and Safety Executive. EH40/2005 workplace exposure limits containing the list of workplace exposure limits for use with the control of substances hazardous to health regulations 2002 (as amended). Available: http://www.hse.gov.uk/pUbns/priced/eh40.pdf [Accessed Nov 2019].

11 Lew V, McKay E, Maze M. Past, present, and future of nitrous oxide. Br Med Bull 2018;125:103-19.

12 American Academy of Pediatric Dentistry. Policy on minimizing occupational health hazards associated with nitrous oxide. Available: https://www.aapd.org/globalassets/media/policies_guidelines/bp_ useofnitrous.pdf [Accessed Nov 2019].

13 National Institute for Occupational Safety and Health. Waste anesthetic gases: occupational hazards in hospitals. Available: https://www.cdc.gov/niosh/docs/2007-151/pdfs/2007-151.pdf?id= 10.26616/NIOSHPUB2007151 [Accessed Nov 2019].

14 Bendall JC, Simpson PM, Middleton PM. Prehospital analgesia in New South Wales, Australia. Prehosp Disaster Med 2011;26:422-6.

15 Grindlay J, Babl FE. Review article: efficacy and safety of methoxyflurane analgesia in the emergency department and prehospital setting. Emerg Med Australas 2009;21:4-11.

16 Porter KM, Dayan AD, Dickerson S, et al. The role of inhaled methoxyflurane in acute pain management. Open Access Emerg Med 2018;10:149-64.

17 Galen Limited. Penthrox 99.9\% 3mL inhalation vapour liquid: Summary of Product Characteristics. Available: http://www. medicines.org.uk/emc/medicine/31391 [Accessed Nov 2019].

18 Mundipharma. Mundipharma announces positive outcome of the European decentralised procedure (DCP) for Penthrox $®$ (methoxyflurane) for emergency relief of moderate to severe pain Available: https://www.mundipharma.com/wp-content/uploads/ 2017/12/Penthrox-approval-release-121217.pdf [Accessed Nov 2019].

19 Mazze RI. Methoxyflurane revisited: tale of an anesthetic from cradle to Grave. Anesthesiology 2006;105:843-6.

20 Dayan AD. Analgesic use of inhaled methoxyflurane: evaluation of its potential nephrotoxicity. Hum Exp Toxicol 2016;35:91-100.

21 Frangos J, Mikkonen A, Down C. Derivation of an occupational exposure limit for an inhalation analgesic methoxyflurane (Penthrox(®)). Regul Toxicol Pharmacol 2016;80:210-25.

22 Ruff R, Kerr S, Kerr D, et al. Occupational exposure to methoxyflurane administered for procedural sedation: an observational study of 40 exposures. Br J Anaesth 2018;120:1435-7.

23 Allison SJ, Docherty PD, Pons D, et al. A bootstrap approach for predicting methoxyflurane occupational exposure in paramedicine. IFAC-PapersOnLine 2017;50:6666-71.

24 3M air monitoring guide: user instructions 3500/3510, 3520/3530, 3550/3551. Available: https://multimedia.3m.com/mws/media/ 15586920/3m-air-monitoring-guide-3500-series-user-instructions. pdf [Accessed Nov 2019].

$253 \mathrm{M}$ technical data bulletin: $3 \mathrm{M}$ organic vapor monitors 3500/3510, 3520/3530, 3550/3551. Available: https://multimedia.3m.com/mws/ media/150655O/3m-organic-vapor-monitors-3500-3510-3520-3530styrene-technical-bulletin.pdf [Accessed Nov 2019].

26 Coffey F, Wright J, Hartshorn S, et al. Stop!: a randomised, double-blind, placebo-controlled study of the efficacy and safety of methoxyflurane for the treatment of acute pain. Emerg Med $J$ 2014;31:613-8

27 Gaskell AL, Jephcott CG, Smithells JR, et al. Self-Administered methoxyflurane for procedural analgesia: experience in a tertiary Australasian centre. Anaesthesia 2016;71:417-23.

28 Wasiak J, Mahar PD, Paul E, et al. Inhaled methoxyflurane for pain and anxiety relief during burn wound care procedures: an Australian case series. Int Wound J 2014;11:74-8.

29 Jacobs IG. Health effects of patients given methoxyflurane in the pre-hospital seeting: a data linkage study. Open Emerg Med $J$ 2010;3:7-13.

303 3TM organic vapor monitor 3500. Available: https://www. 3mcanada.ca/3M/en_CA/company-ca/all-3m-products/ /3MOrganic-Vapour-Monitor-3500B/?N=5002385+3293658197+ 3294529206\&rt=rud [Accessed Nov 2019]. 